tained in a dry state and soon became an article of commercial importance.

With the recovery of these products, the impetus was given to a further exploitation of the other ingredients of the corn, particularly its germ, which contains a large amount of the article, commercially so important, and known as "corn oil." The chemist observed that, due to its lighter specific gravity, the germ could be separated from the body of the crushed corn by a very simple method, and so sound was the reasoning of the chemist leading to an almost mathematical separation of the germ, that the same principle is today still employed, although the invention itself was made over 30 years ago.

The chemist next turned his attention to the soluble solids lost in the water which is used in the softening or steeping of the corn, which water formed an ordinary trade waste. These solids consist of nitrogenous matter, sugars and other carbohydrates, the valuable organic phosphorus compounds and the salts of magnesia and potash.

There are numerous other products which the chemist evolved; among them glycerine and fatty acids from the oil, soap stock from other oil-containing by-products, innumerable special starches for specific purposes, and dextrins and gums of great variety.

These developments have made the products of corn the equals of competing products obtained from wheat, potatoes, sago, rice and other amylaceous sources; and where the products from corn were looked upon at one time as substitutes for the more expensive starch products obtained from other sources, they are sold today upon their own merits, which are recognized and appreciated very keenly by the trade. It goes without saying that the development of our industry would not have made such rapid strides if it had not been for the excellent work of a highly efficient sales organization and for the coopperation of the engineering forces; nevertheless, the effects of the activity of the chemist are noticeable in every direction, and it is not an exaggeration to say that the great American industry of corn products owes its existence primarily to the chemist; while it may be admitted that further expansion of the business will be largely in the direction of commercial development, I am firm in my conviction. that the chemist will continue making his infuence felt in our industry, that the future holds in store a great evolution of the industry and that to this evolution the chemist will contribute, as in the past, a substantial share.

17 BatTery Place, NeW YORE

\section{CONTRIBUTIONS OF THE CHEMIST TO THE ASPHALT INDUSTRY}

BY JAMES LETIS RABE

Secretary The Barber Asphalt Paving Company

Chemistry, in the service of the asphalt industry, has converted it from one which originated on purely empirical lines into one which is now founded on a rational and highly scientifie basis. The development and perfection of the industry from a technical point of view has been made possible only with the aid of chemistry, intelligently associated with practical experience and service tests. During the first two decades of its existence it was conducted on no fixed principle. The hard, refined Trinidad Lake asphalt was fluxed with a heavy petroleum oil, not manufactured especially for the purpose, to form an asphalt cement of a consistency determined solely by personal judgment. This was mixed with hot sand of varying degrees of fineness and with a certain amount of powdered limestone in purely haphazard proportions which were not rationally determined. These mixtures were laid and compressed in the street with most uncertain results, sometimes excellent and sometimes very bad. When the irregularity of such work was recognized, an appeal was made to the chemist, who selected typical samples of these old pavements and resolved them into their constituents by analytical methods. It was found that surfaces which gave good and those that gave poor service were of very different and distinctive characters and that the manner in which they behaved depended upon the original properties of the mineral matter, sand, and powdered stone, as well as the consistency of the asphalt cement used. The chemist devised means of controlling the consistency and regulating the size of the sand by means of sieves, evolving a rational method of construction, which has been followed for twenty years, making the industry, when carried out on such lines, an extremely reliable one, and all work, if controlled by definite tests and analyses, of highly satis. factory character.

The chemist has also given his assistance in the preparation of fluxes or heavy oils of stritable character, and in the fixing of a standard for the grading of the sand and the nature and amount of filler or powdered stone, which enter into an asphalt pavement.

Aside from this, he has studied the nature of the rative bitumens which are the components of asphalt and has differentiated the various types which are found in nature. In fixing the characteristics of the asphalts and the various petroleums from which fluxes and residual pitches are obtainect, he has made it possible to describe these materials with such accuracy in specifications that they are readily differentiated.

He has made a study of the behavior of asphalt surfaces under service tests, and has been enabled to draw valuable conclusions therefrom which are applicable to the improvement and development of the industry. He has studied the physical characteristics of the sand used and of the phenomena connected with its behavior in combination with fine powders. He has demon. strated the fact that the presence of large amounts of this fine powder and filler through the presentation of a very large surface for the adhesion of the bitumen, adds in an enormous degree to the success of an asphalt surface under heavy traffic, in which study the principles of physical chemistry are closely involved. Work along these lines is still being undertaken in the laboratory, and it would seem that equally interesting points are to be developed in the future as in the past, along the lines of chemistry and physics.

Results obtaitned in these directions have been on such a large scale that the data accumulated have been assembled in a book of more than 600 pages by an expert of the company with which the writer is connected.

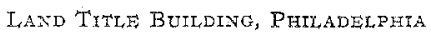

\section{CONTRIBUTIONS OF THE CHEMIST TO THE COTTON- SEED OIL INDUSTRY}

\section{By Daved Wesson}

Manager of the Lechnical Department. Southern Cotton Oil Company In I834, an English traveler in this country, writing about cotton culture, said: "In many places it is usual to manure the fields with the seed not used for sowing; but of late years experience has taught the planters to set a higher value on it as it contains a considerable quantity of oil which is extracted by pressure and is suitable both for burning and painting. This oil may, in the course of years, become an additional source of wealth to the planters."

About twenty years afterwards-shortly prior to our Civil War-mone or two mills were started in. New Orleans. The in.dustry, intertupted by the war, accuired a start shortly afterward, and in 1872 as much as 52,705 tons of seed were crushed. This amounted to 4 per cent of the entire crop of $x, 3 \pi 7,637$ tons. In I9I3, with a production of $6,305,000$ tons, 4,767,800 tons were crushed, or 75.6 per cent of the entire crop. The estimated average cost per ton was $\$ 25.35$, and the total value of the seed alone was $\$ 120,840,000$, while the value of the products was $5156,600,000$. Needless to say that the oil was used for something besides burning and paint.

The first refineries in this country were the Aldige, Union and 